\title{
Familial amyloidosis with cranial neuropathy and corneal lattice dystrophy
}

\author{
G. B O Y S E N, G . G A L A S S , Z K A M I E N I E C K A, \\ J . S CHLAE GER, A N D W TR O J A O R G
}

From the Department of Neurology and Laboratory of Clinical Neurophysiology, Rigshospitalet, and Institute of Neurophysiology, University of Copenhagen, Denmark

SUMMARY Five siblings of a Danish family with slowly progressive involvement of the trigeminal, facial, glossopharyngeal, accessory, and hypoglossal nerves beginning at the age of 55-65 years were examined. All had asymptomatic corneal lattice dystrophy. Clinical and electrophysiological investigations also showed evidence of slight neurogenic involvement of the limbs. Conduction velocity along sensory nerves was normal but amplitude of sensory potentials was severely reduced suggesting an axonal affection which was confirmed by sural nerve biopsy. The neuropathy was secondary to amyloidosis revealed by skin and sural nerve biopsies.

Amyloidosis with cranial nerve involvement which afflicted 207 individuals from 56 Finnish families was described by Meretoja (1973). An autosomal dominant mode of inheritance was found. The disease developed insidiously with onset of facial weakness and dysarthria in the fifth or sixth decades, and was steadily progressive. However, the first detectable sign which occurred in the third to fourth decades was a corneal opacification due to a fine network of filaments. This is known as corneal lattice dystrophy and is caused by amyloid deposits (Meretoja, 1969). Nerves of the extremities were involved at a later stage and to a milder degree. Amyloid deposits were found in almost all organs causing little or no impairment of their function (Meretoja and Teppo, 1971).

The purpose of the study presented in this report was to describe clinical, electrophysiological, and sural nerve biopsy findings in affected members of a Danish family with amyloidosis combined with cranial neuropathy and corneal lattice dystrophy.

The family has lived in Denmark for generations and could not be traced to Finland. The propositus had nine siblings of whom three brothers and one sister were afflicted (Fig. 1). Their mother and her brother had long been dead but were assumed to have had the disease, judging from their facial

\footnotetext{
Address for reprint requests: Dr W. Trojaborg, Laboratory of Clinical Neurophysiology, Rigshospitalet, DK 2100, Blegdamsvei 9, Copenhagen, Denmark.

Accepted 11 May 1979
}

appearance on photographs. The second generation consisted of 22 children aged 17-45 years and none of them had any symptoms of the disease. Seven of the oldest who had a neurological and ophthalmological examination were not affected. The remaining younger children as well as the 29 grandchildren (1-25 years old) were all healthy.

\section{Case reports}

CASE 1

The propositus was a 72 year old farmer who had been healthy until aged 55 years, when he noted involuntary muscular twitches in the face. During the next few years he slowly developed weakness of the facial muscles and tongue resulting in slurred speech. Recently he had noticed numbness distally in the arms.

His appearance was sad, with drooping eyelids, and hanging skin of the face and skull. On his back the skin hung like curtain folds, and on the fingers it also was abnormally slack. He was mentally normal, but his speech was almost incomprehensible. Corneal sensation was decreased and pain sensation was impaired on the lower lip. There was pronounced facial weakness with Bell's phenomenon. Involuntary twitches were noted in the right orbicularis oris muscle and the tongue. The jaw reflex was absent, the soft palate was immobile, and the motility of the vocal cords was reduced. Head lifting and turning was moderately paretic. The tongue was atrophic and could not be 


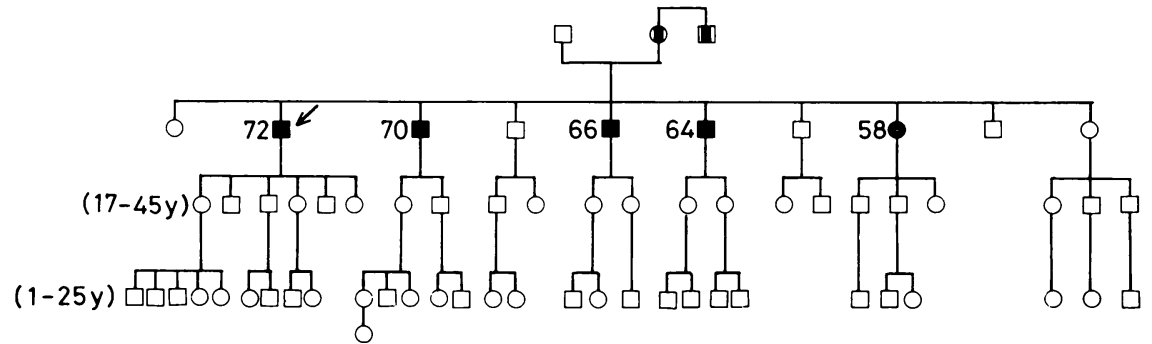

Fig. 1 Pedigree of case 1. Propositus indicated by arrow. Individuals considered to be affected from history are represented by half-filled symbols. Age is given beside symbols.

protruded beyond the teeth nor moved from side to side. There was no limb weakness. The Achilles tendon jerk and the radial reflexes were absent; all other reflexes were normal. The pain and temperature senses were impaired in the finger tips, and he had difficulties in handling and identifying small objects. Vibration sense was decreased in the fingers and absent in the toes and ankles. Appreciation of light touch and pinprick was impaired in the feet; joint position sense was intact.

A slit lamp examination showed lattice corneal dystrophy with multiple greyish streaks in the cornea and incipient posterior pole cataract.

Microscopy of a skin biopsy sample revealed a homogeneous substance around sweat glands and blood vessels. In the polarising light micro- scope it showed green birefringence after Congo red stain.

Laboratory tests revealed a silent chronic lymphatic leukaemia with a leucocyte count of $48 \times 10^{9} / 1 \quad(3.0-8.5)$. There was no hepatosplenomegaly. Platelets numbered $132 \times 10^{9} / 1$ (160-400). Fasting blood sugar was normal, but the glucose tolerance test was of diabetic type. Blood pressure was $160 / 100 \mathrm{mmHg}$. The clinical findings are summarised in Table 1.

CASE 2

This 70 year old man had noticed "hanging" of the face for the last five years. He slowly developed speech difficulties and weakness of the tongue and had noticed decreased sensation in the lower

Table 1 Clinical findings

\begin{tabular}{|c|c|c|c|c|c|}
\hline & Case 1 & Case 2 & Case 3 & Case 4 & Case 5 \\
\hline Sex & Male & Male & Male & Male & Female \\
\hline Age at first examination (yr) & 72 & 70 & 66 & 64 & 58 \\
\hline Lat tice corneal dystrophy & + & + & + & + & + \\
\hline Slackness of skin & + & + & + & - & + \\
\hline Dysarthria & + & + & + & + & - \\
\hline Impaired corneal sensation & + & + & + & + & + \\
\hline $\begin{array}{l}\text { Patchy impairment of pain or touch in the } \\
\text { face }\end{array}$ & + & + & - & - & + \\
\hline Facial mucle weakness and tongue atrophy & + & + & + & + & + \\
\hline Gag reflex & Absent & Weak & Weak & Normal & Normal \\
\hline Jaw reflex & Normal & Absent & Normal & $?$ & Absent \\
\hline Brachioradial reflex & Absent & Normal & Absent & Absent & Normal \\
\hline \multirow[t]{2}{*}{ Achilles reflex } & Absent & Normal & Normal & Absent & Absent \\
\hline & $\mathrm{F} / \mathrm{T}^{*}$ & $\mathbf{F} / \mathbf{T}$ & $\mathbf{F} / \mathbf{T}$ & $\mathbf{F} / \mathbf{T}$ & $\mathbf{F} / \mathbf{T}$ \\
\hline Sensation of pain impaired & $+1+$ & $+1-$ & $-1+$ & $-1+$ & $+1+$ \\
\hline Sensation of touch impaired & $-1+$ & $+1-$ & $-1-$ & $-1-$ & $+1-$ \\
\hline Sensation of vibration impair ed & $+1+$ & $+1+$ & $+1+$ & $+1 \cdot+$ & -+ \\
\hline Sensation of position impaired & $-1-$ & $-1+$ & $-1-$ & $-1+$ & $-1+$ \\
\hline Object identification impaired & + & + & - & - & + \\
\hline Amyloid deposit in bicpsy & Skin + nerve & Skin & Skin + nerve & Skin & Rectum \\
\hline Diabetes mellitus, latent/manifest & $+1-$ & $? / ?$ & $+1-$ & $-1+$ & $-1-$ \\
\hline \multicolumn{6}{|l|}{ Immunoglobulins in serum $(\mathrm{g} / 1)$} \\
\hline IgG (normal 6.82-15.7) & 7.7 & 11.0 & 15.5 & 21.7 & 15.4 \\
\hline IgA (normal 0.56-3.30) & 0.80 & 3.28 & 1.89 & 2.68 & 0.65 \\
\hline IgM (nornıal 0.18-1.29) & 0.21 & 0.53 & 0.70 & 0.93 & 2.06 \\
\hline
\end{tabular}

* $F=$ fingers, $T=$ tocs 
lip. He complained of numbness of the fingertips and "pins and needles" paraesthesiae in the three radial fingers on both sides especially at night. Raynaud's phenomenon had been present in the hands for several years.

The symptomatology and clinical findings in this and the subsequent cases are summarised in Table 1 .

\section{CASE 3}

This patient was a 66 year old man who received disability pension because of chronic bronchitis. At the age of 59 years he noted twitches in the face. Facial weakness, swallowing and speech difficulties developed slowly during the next few years. He was admitted to hospital because of respiratory problems and bilateral vocal cord paresis. $\mathrm{He}$ refused to undergo tracheostomy.

\section{CASE 4}

This 64 year old man had had pulmonary emphysema as a result of chronic bronchitis since the age of 54 years. At the age of 57 years he had noticed drooping eyelids, slowly increasing facial weakness, and chewing difficulties. When 61 years old, tracheostomy was performed because of increasing respiratory insufficiency and bilateral vocal cord paresis. At that time he was diagnosed as having mild diabetes and was treated with oral medication. At the age of 64 years he suffered an acute myocardial infarction.

\section{CASE 5}

This patient, a 58 year old, previous healthy woman, had delivered three children. For some years she had had Raynaud's phenomenon in the hands, and had received diuretics for arterial hypertension. Recently her family had noticed that her lower lip was "hanging," and that crumbs would gather in the corners of her mouth. She had noted involuntary twitches around the lips.

\section{Methods}

\section{ELECTROMYOGRAPHY}

In all patients the facial muscles and the tongue were examined as well as the abductor pollicis brevis, the anterior tibial, and the extensor digitorum brevis muscles. The criteria used were (1) the pattern of activity at full effort, (2) the amplitude of its envelope curve, (3) the number of sites in which fibrillation potentials and positive sharp waves were recorded outside the endplate zone, and (4) the mean potential duration and amplitude of at least 20 randomly sampled motor unit potentials. Findings were evaluated by comparison with normal muscles matched for age (Rosenfalck and Rosenfalck, 1975).

\section{CONDUCTION STUDIES}

The facial, median, ulnar, and sural nerves were examined. The facial nerve was stimulated by needle electrodes. The near nerve electrode was placed at the stylomastoid foramen. Concentric electrodes were used for recording and were placed in the orbicularis oris, the triangularis, and the frontalis muscles. The muscle potentials were evoked by stimuli four to five times the threshold (Trojaborg, 1977).

The conduction velocity along motor and sensory fibres of the median and ulnar nerves and along the sural nerve was determined according to methods previously described (Buchthal and Rosenfalck, 1966; Behse and Buchthal, 1971). In short, the median and ulnar nerves were stimulated by needle electrodes placed at the wrist. Responses were evoked in the abductor pollicis brevis and the abductor digiti minimi muscles by supramaximal stimulation and recorded between a wire electrode placed in the endplate region and a ring electrode placed at the distal phalanx of digits 1 and 5 respectively. Sensory fibres were stimulated by surface electrodes placed around digits 1 , 3 , and 5 .

The sural nerve was stimulated by needle electrodes placed at the lateral malleolus, and a sensory action potential was recorded by needle electrodes placed at the calf. To determine minimum conduction velocity along sensory fibres, and when amplitude of sensory potentials was below $2 \mu \mathrm{V}$, electronic averaging of 500 and 1000 traces was used (Buchthal et al., 1974).

\section{SURAL NERVE BIOPSY}

This was performed in two patients (cases 1 and 3) according to the method described by Behse et al. (1972). In short, a $30 \mathrm{~mm}$ length of the sural nerve was removed in toto, just proximal to the lateral malleolus. The samples were fixed in $2 \%$ buffered glutaraldehyde ( $36 \mathrm{hr})$ and post-fixed in $1 \%$ buffered osmium tetroxide $(2 \mathrm{hr})$. Samples for light and electron microscopy were dehydrated in graded concentrations of ethanol and embedded in Epon 812 . Transverse sections ( $3 \mu \mathrm{m}$ thick) were stained with $1 \%$ paraphenylenediamine and ultrathin sections for electron microscopy were stained with uranyl acetate and lead citrate. Fresh frozen sections were stained with Congo red.

In each biopsy specimen, the transverse endoneurial area was measured as described by Behse et al. (1974). In an area of $0.2-0.3 \mathrm{~mm}^{2}$ 
sampled from all the fascicles, the total number and size distribution of myelinated fibres, the number of groups of three or more regenerating fibres (clusters) were determined by light microscopy. In the electron microscope, areas of 7000$15000 \mu \mathrm{m}^{2}$ from two different fascicles were analysed at magnifications of 10000,20000 , and 50000 times with respect to abnormality in the structure of unmyelinated fibres and in the axon and myelin sheath of the myelinated fibres. The incidence of bands of Büngner was determined. Unmyelinated fibres were identified using the criteria of Behse et al. (1975). Their number and size distribution, the occurrence of degenerating fibres characterised by loss of axonal organelles, and the number of Schwann cell subunits containing or devoid of axons were determined. In both nerves, myelinated fibres 27 of case 1 and 57 of case 3 of $8-10 \mathrm{~mm}$ length and more than $7 \mu \mathrm{m}$ in diameter were teased in $60 \%$ glycerol. The incidence of abnormality was determined at a magnification of $\times 200$ for the length and $\times 750$ for the diameter using the criteria of Behse and Buchthal (1977): (1) segmental demyelination, (2) widening of the nodal gap up to more than $10 \mu \mathrm{m}$ and paranodal demyelination over a length up to $300 \mu \mathrm{m}$, (3) paranodal swelling as enlargement of the myelin sheath at the nodal region up to more than $22 \mu \mathrm{m}$, (4) regenerated fibres, (5) remyelinated segments in series, (6) solitary intercalated segments, and (7) abnormality of the myelin sheath as cylindrical or spindle shape balloons of $16-23 \mu \mathrm{m}$ in diameter over a length of $150-450 \mu \mathrm{m}$, not occurring in the immediate vicinity of the nodes of Ranvier.

\section{Results}

\section{ELECTROMYOGRAPHY}

The findings in the five patients are summarised in Table 2. In all patients the EMG of facial muscles and tongue showed evidence of chronic partial denervation-that is, discrete activity or

Table 2 Electromyographic findings

\begin{tabular}{lllll}
\hline Case & Sex & $\begin{array}{l}\text { Facial muscles } \\
\text { and tongue }\end{array}$ & $\begin{array}{l}\text { Abductor } \\
\text { pollicis brevis } \\
\text { muscle }\end{array}$ & $\begin{array}{l}\text { Anterior tibial } \\
\text { or extensor } \\
\text { digitorum brevis } \\
\text { muscle }\end{array}$ \\
\hline 1 & M & + & + & + \\
2 & M & + & + & + \\
3 & M & + & + & + \\
4 & M & + & + & + \\
5 & F & + & B & N \\
\hline
\end{tabular}

$+=$ chronic partial denervation, $\mathrm{N}=$ normal, $\mathrm{B}=$ borderline. a reduced recruitment pattern during full effort, an increased mean potential duration and amplitude or both, and an increased incidence of polyphasic potentials. Fibrillation potentials and positive sharp waves, if present, were rare. Similar findings were present in the abductor pollicis brevis muscle in all patients but one (case 5).

In the anterior tibial or extensor digitorum brevis muscles the EMG showed partial chronic denervation in four of the five patients.

\section{CONDUCTION STUDIES}

The latency to the facial muscles is shown in Fig. 2. In all patients one or more of the latencies to the facial muscles were outside the normal range. In three, the latency to one of the three facial muscles examined was within the normal range. In two patients conduction along motor and sensory fibres of the median nerve was slow in the distal segment whereas it was normal along the ulnar nerve, indicating a mild carpal tunnel syndrome (cases 2 and 3). Otherwise motor and sensory conduction velocities along the median and ulnar nerves were normal, but in all except one (case 5) the amplitude of sensory action potentials was significantly reduced (Figs. 3 and 4).

Conduction velocity along the sural nerve was normal or at the lower range of normal in all

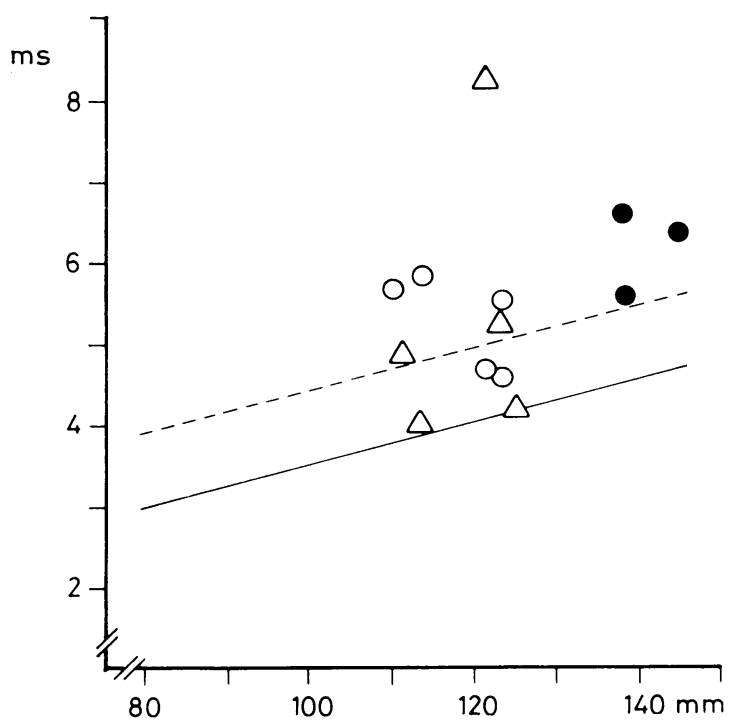

Fig. 2 Latency of orbicularis oris $(\bigcirc)$, triangularis $(\Delta)$, and frontalis $(\bigcirc)$ muscles in relation to distance between site of stimulation and recording in five siblings with amyloid cranial neuropathy. The thick line represents the regression line, the dashed line the $99 \%$ confidence range in normal subjects (Trojaborg, 1977). 

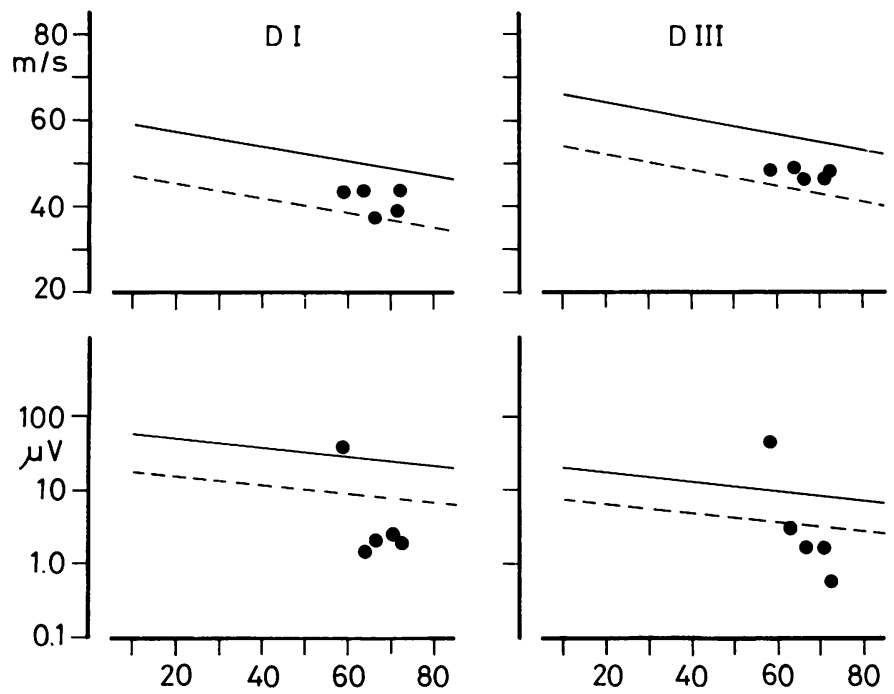

Fig. 4 Sensory conduction velocity along

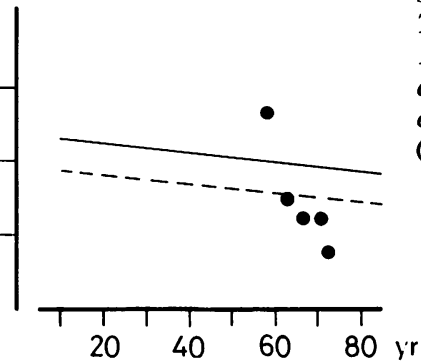

Sensory conduction velocity alon the median nerve from digits 1 and 3 to wrist (above) and amplitude of sensory potentials (log scale, below). The dots represent the value from cases $1-5$, the thick line the regression line, and the dashed line the lower $99 \%$ confidence limit in normal subjects (Rosenfalck and Rosenfalck, 1975).
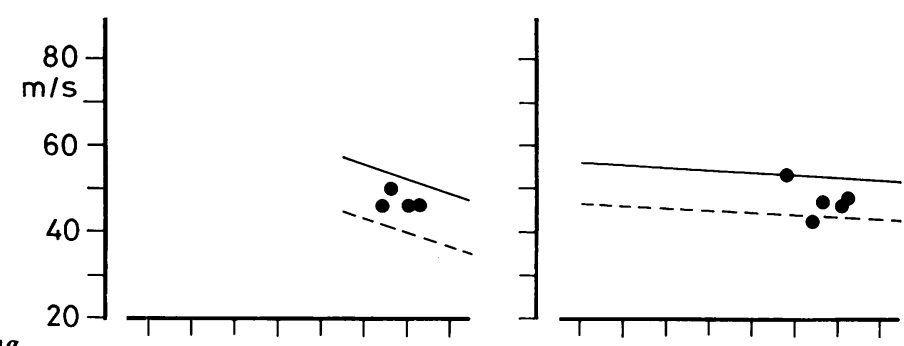

the ulnar nerve from digits 5 to wrist (above, left) and sural nerve from malleolus lateralis to calf (above, right) and amplitude of sensory potentials (log scale, below). Symbols as in Fig. 3.
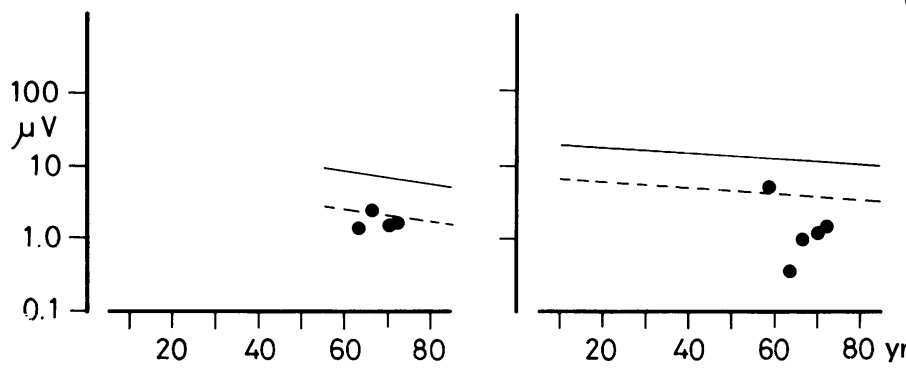

patients whereas the amplitude of the sensory action potential was severely reduced in all but one (Fig. 4). The minimum conduction velocity along sensory fibres of the median, ulnar, and sural nerves was as in normal nerves $(12-18 \mathrm{~m} / \mathrm{s})$ suggesting that regeneration was not a prominent feature of the disorder.

SURAL NERVE BIOPSY

In case 1 , the light microscopy showed amorphous deposits of material with characteristics of amyloid in perineurium and in the wall of epineural vessels of middle calibre. The deposits showed green birefringence with polarising microscopy after Congo red stain. In case 3, amyloid masses could not be identified after the specific stain in the light microscope at low power. In both cases electron microscopy showed amyloid fibres situated in the perineurium. No deposits were seen in the endoneurium. The amyloid filaments seemed to be in close association with proliferation of collagen fibres and the basal lamina of the perineural cells was interrupted and possibly invaded by amyloid (Fig. 5). Onion bulb formations were not found by light or electron microscopy. 


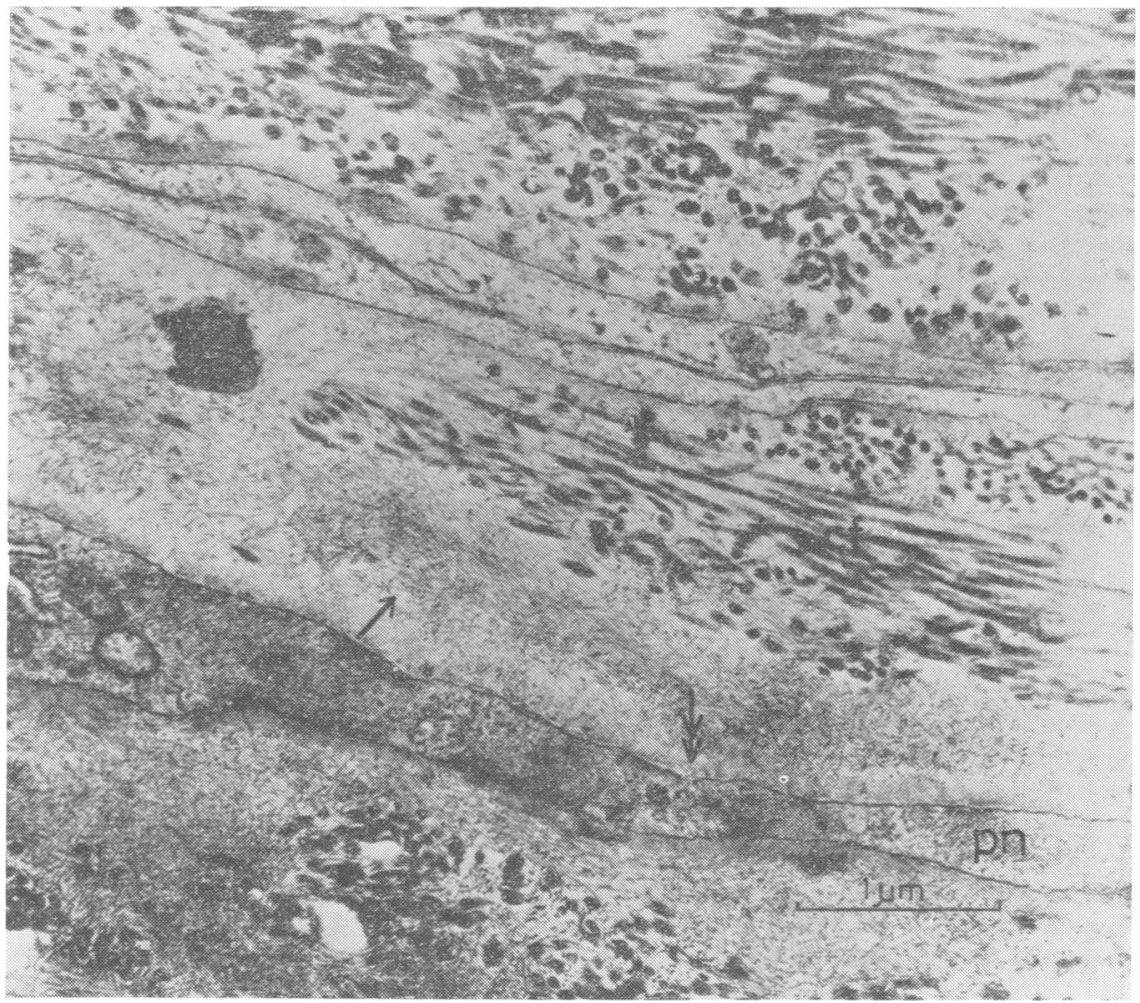

Fig. 5 Electron micrograph from sural nerve of case 3 showing amyloid fibrils (arrow). In the perineural cell (pn) below, a defect of the membrane can be seen (double arrow). Original magnification $\times 50000 . c f=$ collagen fibrils.

The number of myelinated fibres (case 1) and the fibre density per $\mathrm{mm}^{2}$ (case 3 ) were diminished. The diminution involved especially the fibres of large calibre $(>7 \mu \mathrm{m})$. Regeneration of nerve fibres, evidenced by presence of clusters, was pronounced in case $3\left(102 \mathrm{~mm}^{2}\right)$ and within the normal range in case 1 . The histogram was bimodal and skewed in both (Fig. 6). Six fibres of abnormally large diameter $(>18 \mu \mathrm{m})$ were seen in case 1 .

\section{TEASED FIBRES}

Abnormalities were present in $75 \%$ and $81 \%$ of the fibres (cases 1 and 3 respectively) compared with at most $30 \%$ in control nerves (Fig. 7). Multifocal remyelination was a prominent feature in both nerves, present in $40 \%$ of the fibres. Segmental demyelination did not occur in case 1 and it was seen only in two fibres in case 3 . Similarly, paranodal demyelination and solitary intercalated segments indicating a local process of repair were rare $(4-5 \%)$.

Fibies showing shortening of the internodes were common in case $3(41 \%)$, being at the upper limit of normal in case 1. Paranodal swelling, more often combined with remyelinated segments in series and cylindrical or spindle shape enlargements of the myelin sheath, occurred in case 1 only.

ELECTRON MICROSCOPY OF MYELINATED FIBRES

The cross-sectional area analysed showed 15 fibres in case 1 with a diameter exceeding $10 \mu \mathrm{m}, 10$ of which had deformed small axons (1.3-4.5 $\mu \mathrm{m})$ and disorganised myelin sheath, but the axonal organelles seemed normal. In one fibre, both the axon and the myelin were disintegrating. The increased incidence of bands of Büngner (564) in this nerve was the most prominent feature indicating fibre loss. In case 3 , the cross-sectional area examined showed three myelinated fibres about $10 \mu \mathrm{m}$ in diameter with normal axon and myelin sheath.

ELECTRON MICROSCOPY OF UNMYELINATED FIBRES The cross-sectional area analysed showed advanced 


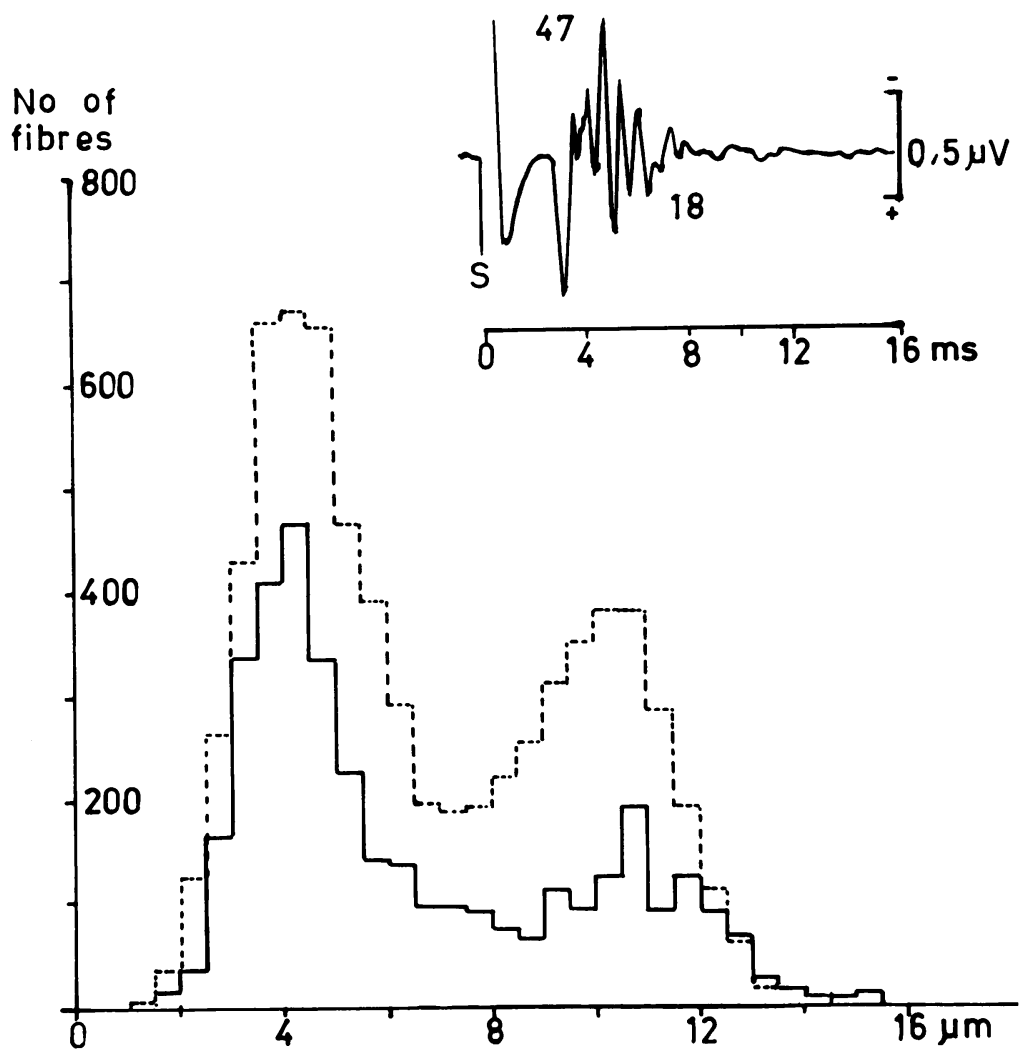

Fig. 6 Histogram of myelinated fibres in sural nerve from case 1 (full line) and from control nerves (dashed line, Behse et al., 1975) showing a bimodal distribution, with a reduced number of fibres (3600 compared with 5000-9500 in normal nerve). Above to the right, the sensory action potential recorded over the sural nerve by electronic averaging of 1024 stimuli applied to the nerve at the lateral malleolus. The recording was performed just before the sural nerve was biopsied. The figure above and below the trace indicates the fastest and slowest conduction velocity in $\mathrm{m} / \mathrm{s}$.

degenerative changes in both nerves. The total number of unmyelinated fibres was reduced, and there was an increased number of Schwann cell subunits devoid of axons and a low number of Schwann cell subunits containing unmyelinated fibres. In both nerves the size distribution was unimodal. The number of unmyelinated fibres of small calibre $(<0.8 \mu \mathrm{m})$ was within the normal range in both cases (Table 3 ).

\section{Discussion}

The clinical neurological pattern in our five patien's is similar to that of the Finnish families with cranial neuropathy and corneal lattice dystrophy (Meretoja, 1969, 1973). Although not confirmed clinically, it is reasonable to suggest that the mother of the propositus of our family and his maternal uncle were affected by the same disorder from the history supported by photographs. This is consistent with an autosomal dominantly inherited disease as described by Meretoja (1973).

In the series of 207 cases "upper facial paresis was a virtually constant feature in patients over 40 years of age" (Meretoja, 1973). Subjects below 30 years of age were without history, signs, or symptoms of neuromuscular disorder but had a few typical corneal lattice lines in both eyes. Onset of corneal lattice dystrophy occurred usually between the third and fourth decades. The eye disorder was more often asymptomatic than symptomatic (Meretoja, 1969).

The children or nephews of the propositus in the 

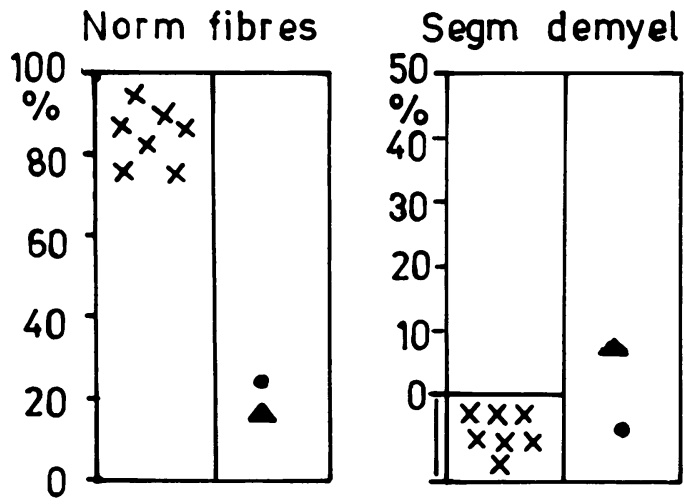

Abn nodes

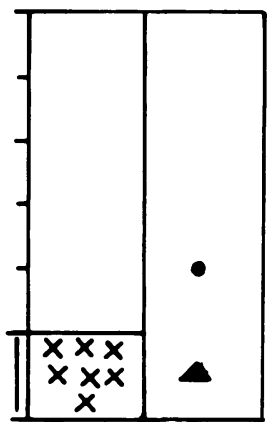

Intercalated segm

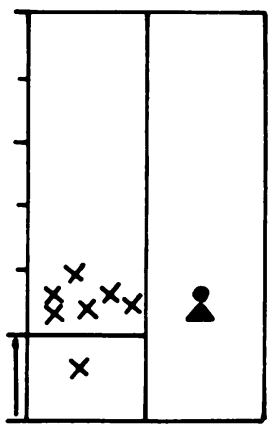

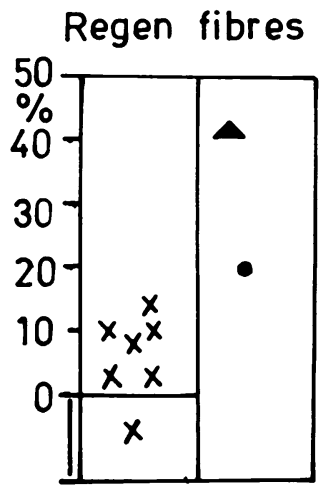

Remyel segm

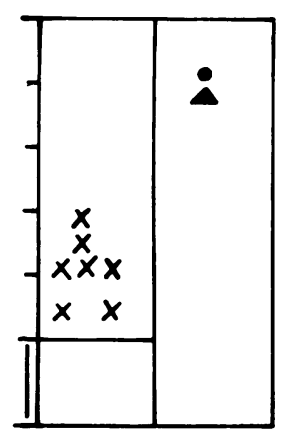

Abn myelin

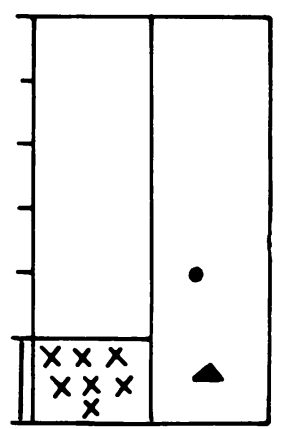

Fig. 7 Incidence of abnormalities in teased fibres of sural nerve from cases $1(O)$ and $3(\Delta)$ compared with control nerves from six normal subjects $(X)$ (Behse et al., 1975). Abnormal nodes refer to paranodal demyelination.

Table 3 Unmyelinated sural nerve fibres and Schwann cells

\begin{tabular}{|c|c|c|c|}
\hline & \multirow{2}{*}{$\begin{array}{l}\text { Number of } C \\
\text { fibres }\end{array}$} & \multicolumn{2}{|c|}{ Number of Schwann cell subunits } \\
\hline & & Devoid of axons & Containing axons \\
\hline Case 1 & 11.601 & $\begin{array}{l}14.527 \\
(58 \%)\end{array}$ & $\begin{array}{l}10.626 \\
(42 \%)\end{array}$ \\
\hline Case $3^{*}$ & 12.980 & $\begin{array}{l}6.691 \\
(36 \%)\end{array}$ & $\begin{array}{l}11.932 \\
(64 \%)\end{array}$ \\
\hline $\begin{array}{l}\text { Control } \\
\text { nerves } \dagger \\
(n=6)\end{array}$ & $20.100-37.500$ & $\begin{array}{r}900-5.700 \\
(7-18 \%)\end{array}$ & $\begin{array}{l}12.600-29.300 \\
(93-82 \%)\end{array}$ \\
\hline
\end{tabular}

*Fascicular biopsy

tfrom Behse et al. (1975)

present series were between 17-45 years. Of these, seven to eight can be predicted to develop symptoms and signs of the disorder sooner or later. None of them had signs or symptoms of cranial neuropathy or of corneal lattice dystrophy. However, in our family neuropathy did not start until the age of 55 years. The oldest living member of the family (case 1) was the most severely affected clinically and the youngest (case 5) the least so, exemplifying the progressiveness of the disease with age. This was also manifested electrophysiologically. In case 5 there was electromyographic evidence of chronic partial denervation in facial muscles and the tongue only, whereas distal muscles of upper and lower extremities were normal. Moreover case 5 was the only one who had normal amplitude of sensory potentials of median and sural nerves. These findings make it less likely that a carrier of the disease can be recognised electrophysiologically. In familial amyloid neuropathy of the Portuguese type, however, Luis (1978) found absent or low voltage sural nerve potentials in eight of 16 clinically unaffected members of 10 affected families.

Seven subjects of the offspring aged 39-47 years examined with a slit lamp did not have corneal lattice dystrophy. The remainder have not yet been examined ophthalmologically, a method by which it should be possible to predict members who are going to be afflicted (Meretoja, 1973). 
Familial cranial neuropathy deviates in many respects from other varieties of hereditary and primary amyloidosis (Trotter et al., 1977) complicated by neuropathic involvement. These disorders have been reviewed recently (Thomas, 1975). First, the age of onset is much later in cranial neuropathies than in other varieties of the disorder; secondly, there is no, or only mild, involvement of the autonomic nervous system which is so characteristic of the Portuguese type of neuropathy (Andrade, 1952); thirdly, there is no loss of thermal sensation and pain which is the dominating feature of the Portuguese type of neuropathy, leading to burning ulcers in the feet.

Electrophysiological findings show some similarities between different types of amyloid neuropathies. Motor conduction velocity is usually normal or only mildly slowed. Of the five patients with cranial neuropathy examined by Meretoja (1969) only one had slowing along motor fibres, and similar findings have been reported in patients with amyloid polyneuropathy (Dyck and Lambert, 1969; Mahloudji et al., 1969; Coimbra and Andrade, 1971a; Thomas and King, 1974; Luis, 1978). Mild slowing in distal fibres in the median nerve has been attributed to compression at the wrist from amyloid deposits beneath the flexor retinaculum (Lambird and Hartmann, 1969; Mahloudji et al., 1969). Similarly, we found electrophysiological changes suggestive of a carpal tunnel syndrome in two patients.

Sensory conduction was not studied by Meretoja and coworkers $(1969,1971,1972,1973)$. In our patients we found normal or nearly normal conduction velocities along median, ulnar, and sural nerves. The only abnormality was a severely reduced amplitude of sensory potentials in all patients but one.

The findings of normal or near normal conduction velocities along median, ulnar, and sural nerves in spite of severe reduction in amplitude of sensory potentials are compatible with an axonal neuropathy. This assumption was confirmed by sural nerve biopsy in two patients. In one (case 1) the total number of myelinated fibres was reduced to about half the normal and in the other (case 3, fascicular biopsy) the fibre density per $\mathrm{mm}^{2}$ was significantly diminished. Large diameter fibres were more affected than smaller ones, but there was no evidence of segmental demyelination. This is in contrast to the findings of Meretoja and Teppo (1971). They stated that small diameter fibres were more affected than larger ones, and that there was a considerable loss of myelin sheaths especially of small calibre fibres. However, their findings were not quantitated.
Unmyelinated fibres were not examined by Meretoja and Teppo (1971). We found a reduction in the total number of unmyelinated fibres to about half the normal and two to three times higher incidence of Schwann cells devoid of axons compared to findings in control nerves. This is compatible with clinical findings of impaired pain and temperature sense. Loss of pain and temperature sensation and prominent autonomic symptoms were not part of the neurological pattern in our patients, contrary to the Portuguese type of amyloid neuropathy, where the clinical findings are compatible with virtual absence of unmyelinated fibres (Dyck and Lambert, 1969; Thomas and King, 1974).

We found amyloid deposits localised to the perineurium in both patients, but in one (case 3) it could be seen in the electron microscope only, although this patient was as severely affected clinically and electrophysiologically as case 1 . Meretoja and Teppo (1971) at necropsy also found amyloid in the endoneurium of peripheral nerves, and in the facial nerve amyloid deposits filled the major part of the transverse section, almost destroying some branches.

The pathogenesis of neuropathy in relation to amyloidosis is not clear and it has been discussed whether or not nerve fibre damage is secondary to amyloid deposits (Coimbra and Andrade, 1971b; Thomas and King, 1974). The discrete amyloid deposit in the sural nerve of our patients would favour the assumption that axonal loss preceded the presence of amyloid as suggested by Coimbra and Andrade (1971), although as argued by Thomas and King (1974) this has not been established conclusively. Amyloid deposits may be present in dorsal root ganglia and spinal nerves (Horta and Trincao, 1963) and exert a mechanical effect on nerve fibres at these sites. Distortion of nerve fibres by amyloid deposits was demonstrated by Dyck and Lambert (1969) and by Thomas and King (1974).

In 1959 Klaus and coworkers described three sisters aged 64-77 years who over 10-15 years had increasing weakness of muscles innervated by the trigeminal, facial, and hypoglossal nerves. At examination they were found to have changes in the cornea ("gittriger Hornhautdystrophie") which seem to be identical with corneal lattice dystrophy. Moreover they all had skin changes diagnosed as cutis hyperelastica. Although the patients were classified as a familial bulbar paralytic type of amyotrophic lateral sclerosis and although they were not examined for amyloid, it is likely, as also suggested by Meretoja (1969), that they represent a syndrome similar to the 
Finnish and Danish families. Winkelman et al. (1971) described a similar syndrome in a 77 year old woman from the Netherlands whose brother also suffered from peripheral neuropathy, skin changes, and corneal lattice dystrophy secondary to amyloidosis.

As to the immunoglobulins in serum, no distinct pattern was found. One patient (case 4) had an increased $\mathrm{IgG}$, and another (case 5) an increased IgM; in the remaining patients all fractions were within the normal range (Table 1). These findings are consistent with those of Meretoja et al. (1972)

The genetic fault, which may involve different genes in amyloid neuropathy of varying expression, is not known. Biochemical studies have so far not contributed to diagnosis or classification of the neuropathies. This is still based on clinical findings and demonstration of amyloid deposits in skin or rectal biopsies.

We would like to thank Mr F. Carlsen of the Institute of Physics II, University of Copenhagen, for producing electronmicrographs and for assistance in their evaluation.

\section{References}

Andrade, C. (1952). A peculiar form of peripheral neuropathy. Familial atypical generalised amyloidosis with special involvement of the peripheral nerves. Brain, 75, 408-427.

Behse, F., and Buchthal, F. (1971). Normal sensory conduction in the nerves of the leg in man. Journal of Neurology, Neurosurgery, and Psychiatry, 34, 404-414.

Behse, F., and Buchthal, F. (1977). Peroneal muscular atrophy and related disorders. Histological findings in sural nerves. Brain, 100, 67-85.

Behse, F., Buchthal, F., Carlsen, F., and Knappeis, G. G. (1972). Hereditary neuropathy with liability to pressure palsies. Electrophysiological and histcpathological aspects. Brain, 95, 777-794.

Behse, F., Buchthal, F., Carlsen, F., and Knappeis, G. G. (1974). Endoneurial space and its constituents in the sural nerve of patients witl neuropathy. Brain, 97, 773-784.

Behse, F., Buchthal, F., Carlsen, F., and Knappeis, G. G. (1975). Unmyelinated fibres and Schwann cells of sural nerve in neuropathy. Brain, 98, 493510.

Buchthal, F., and Rocenfalck, A. (1966). Evoked action potentials and conduction velocity in human sensory nerves. Brain Research, 3, 1-122.

Buchthal, F., Rosenfalck, A., and Trojaborg, W. (1974). Electrophysiological findings in entrapment of the median nerve at wrist and elbow. Journal of Neurology, Neurosurgery, and Psychiatry, 37, 340360 .
Coimbra, A., and Andrade, C. (1971a). Familial amyloid polyneuropathy. An electron microscope study of the peripheral nerve in five cases. I. Interstitial changes. Brain, 94, 199-206.

Coimbra, A., and Andrade, C. (1971b). Familial amyloid polyneuropathy. An electron microscope study of the peripheral nerve in five cases. II. Nerve fibre changes. Brain, 94, 207-212.

Dyck, P. J., and Lambert, E. H. (1969). Dissociated sensation in amyloidosis. Compound action potential, quantitative histologic and teased-fiber and electron microscopic studies of sural nerve biopsies. Archives of Neurology (Chicago), 20, 490 507.

Horta, J. da Silva, and Trincao, R. (1963). Anatomie pathologique de la paramyloidose du "type portugais”. Acta Neuropathologica, Suppl. II, 54 65.

Klaus, E., Freyberger, E., Karka, G., and Vodicka, F. (1959). Familiäres vorkommen von bulbärparalütischer form der amyotrophischen lateralsklerosen mit gittriger Hornhautdystrophie und Cutis hyperelastica bei drei Schwestern. Psychiatria et Neurologia (Basel), 139, 79-97.

Lambird, P. A., and Hartmann, W. H. (1969). Hereditary amyloidosis, the flexor retinaculum and the carpal tunnel syndrome. American Journal of Clinical Pathology, 52, 714-719.

Luis, M. L. S. (1978). Electroneurophysiological studies in familial amyloid polyneuropathyPoriuguese type. Journal of Neurology, Neurosurgery, and Psychiatry, 41, 847-850.

Mahloudji, M., Teasdall, R. D., Adamkiewicz, J. J., Hartmann, W. H., Lambird, R. A., and McKusick, V. A. (1969). The genetic amyloidosis, with particular reference to hereditary neuropathic, amyloidosis, type II (Indiana or Rukavina type. Medicine (Baltimore), 48, 1-37.

Meretoja, J. (1969). Familial systemic paramyloidosis with lattice dystrophia of the cornea, progressive cranial neuropathy, skin changes and various internal symptoms. Annals of Clinical Research, 1, 314-324.

Meretoja, J. (1973). Genetic aspects of familial amyloidosis with corneal lattice dystrophy and cranial neuropathy. Clinical Genetics, 4, 173-185.

Meretoja, J., and Teppo, L. (1971). Histopathological findings of familial amyloidosis with cranial neuropathy as principal manifestation. Acta Pathologica et Microbiologica Scandinavica, 79, 432-440.

Meretoja, J., Jokinen, E. J., Collan, Y., and Lähdevirta, J. (1972). Renal biopsy findings in familial amyloidosis with corneal lattice dystrophy. An immuno-histochemical, light-microscopical and electron-microscopical study. Acta Pathologica Microbiologica Scandinavica, 80, Suppl. 233, 228238.

Rosenfalck, P., and Rosenfalck, A. (1975). Electromyography, Sensory and Motor Conduction. Findings in Normal Subjects, p. 49. Rigshospitalets Forlag: Copenhagen. 
Thomas, P. K. (1975). Genetic factors in amyloidosis. Trotter, J. L., Engel, K. W., and Ignaczak, T. F. Journal of Medical Genetics, 12, 317-326.

Thomas, P. K., and King, R. H. M. (1974). Peripheral nerve changes in amyloid neuropathy. Brain, 97, 395-406.

Trojaborg, W. (1977). Does cross-innervation occur after facial palsy? Journal of Neurology, Neurosurgery, and Psychiatry, 40, 712-717. (1977). Amyloidosis with plasma cell dyscrasia. Archives of Neurology (Chicago), 34, 209-214.

Winkelman, J. E., Delleman, J. W., and Ansink, J. J. (1971). Ein hereditäres Syndrom, bestehend aus peripherer Polyneuropathie, Hautveränderungen und gittriger Dystrophie der Hornhaut. Klinische Monatsblätter für Augenheilkunde, 159, 618-623. 